Supporting Information

\title{
Entropy-Driven Assembly of Nanoparticles within Emulsion- Evaporative Block Copolymer Particles: Crusted, Seeded, and Alternate-Layered Onions
}

Meng Xu ${ }^{1}$, Kang Hee Ku ${ }^{1}$, Young Jun Lee ${ }^{1}$, Jaeman J. Shin ${ }^{1}$, Eun Ji Kim ${ }^{1}$, Se Gyu Jang ${ }^{2}$, Hongseok $\mathrm{Yun}^{*, 1}$, and Bumjoon J. Kim ${ }^{* 1}$

${ }^{1}$ Department of Chemical and Biomolecular Engineering, Korea Advanced Institute of Science and Technology (KAIST), Daejeon 34141, Republic of Korea

${ }^{2}$ Functional Composite Materials Research Center, Korea Institute of Science and Technology (KIST), Jeonbuk 55324, Republic of Korea

* E-mail: bumjoonkim@kaist.ac.kr (B. J. K.), hongsyun@kaist.ac.kr (H. Y.) 


\section{- Supporting Figures and Table}
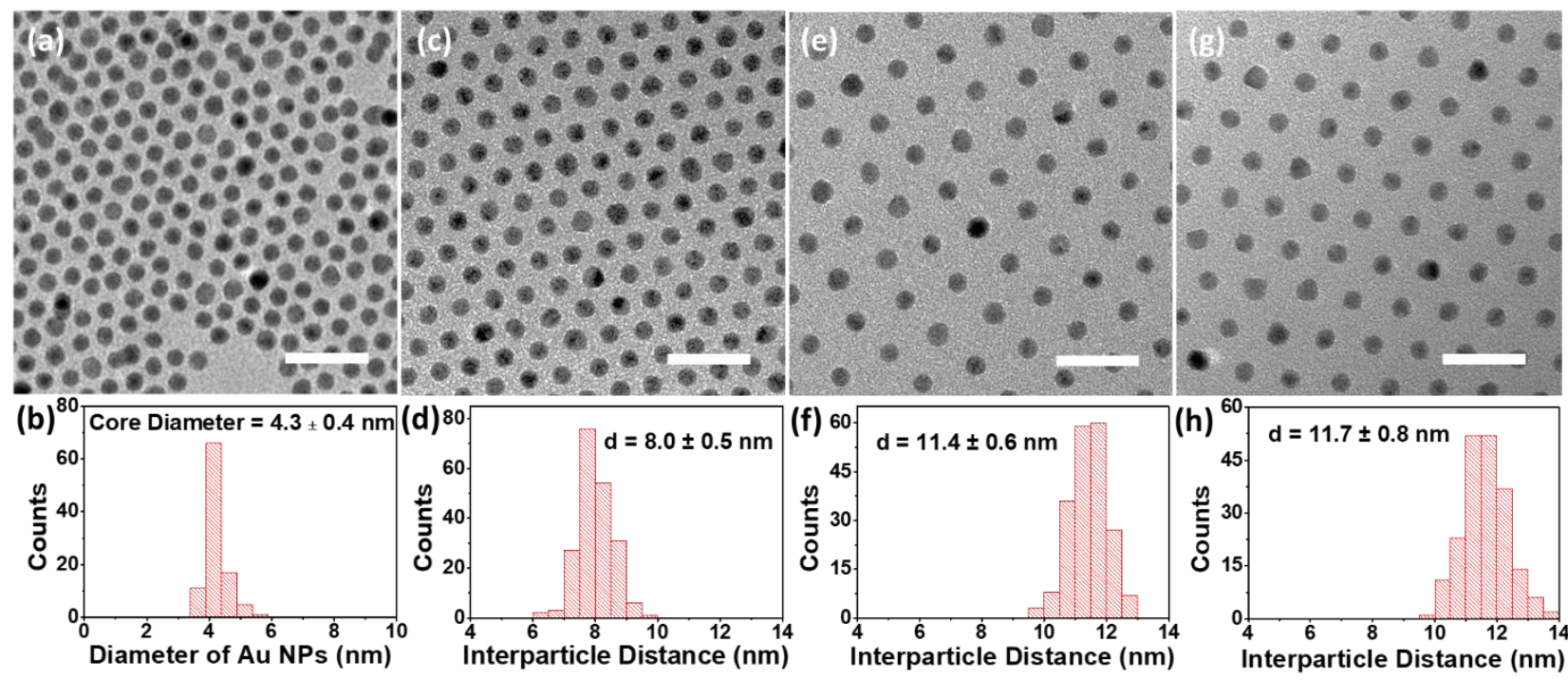

Figure S1. Characterization of $\mathrm{Au} @ \mathrm{PS}$ with different $M_{\mathrm{n}}$ of PS ligands. TEM images and histograms of (a, b) as-synthesized Au NPs, (c, d) 4Au@2kPS, (e, f) 4Au@4kPS, and (g, h)4Au@6kPS. Scale bars are $20 \mathrm{~nm}$. The average core diameter of the Au NPs was $4.3 \pm 0.4 \mathrm{~nm}$, and the interparticle distance $(d)$ was $8.0 \pm 0.5,11.4 \pm 0.6$, and $11.7 \pm 0.8 \mathrm{~nm}$ for 4Au@2kPS, 4Au@4kPS, and 4Au@6kPS, respectively. 
(a)
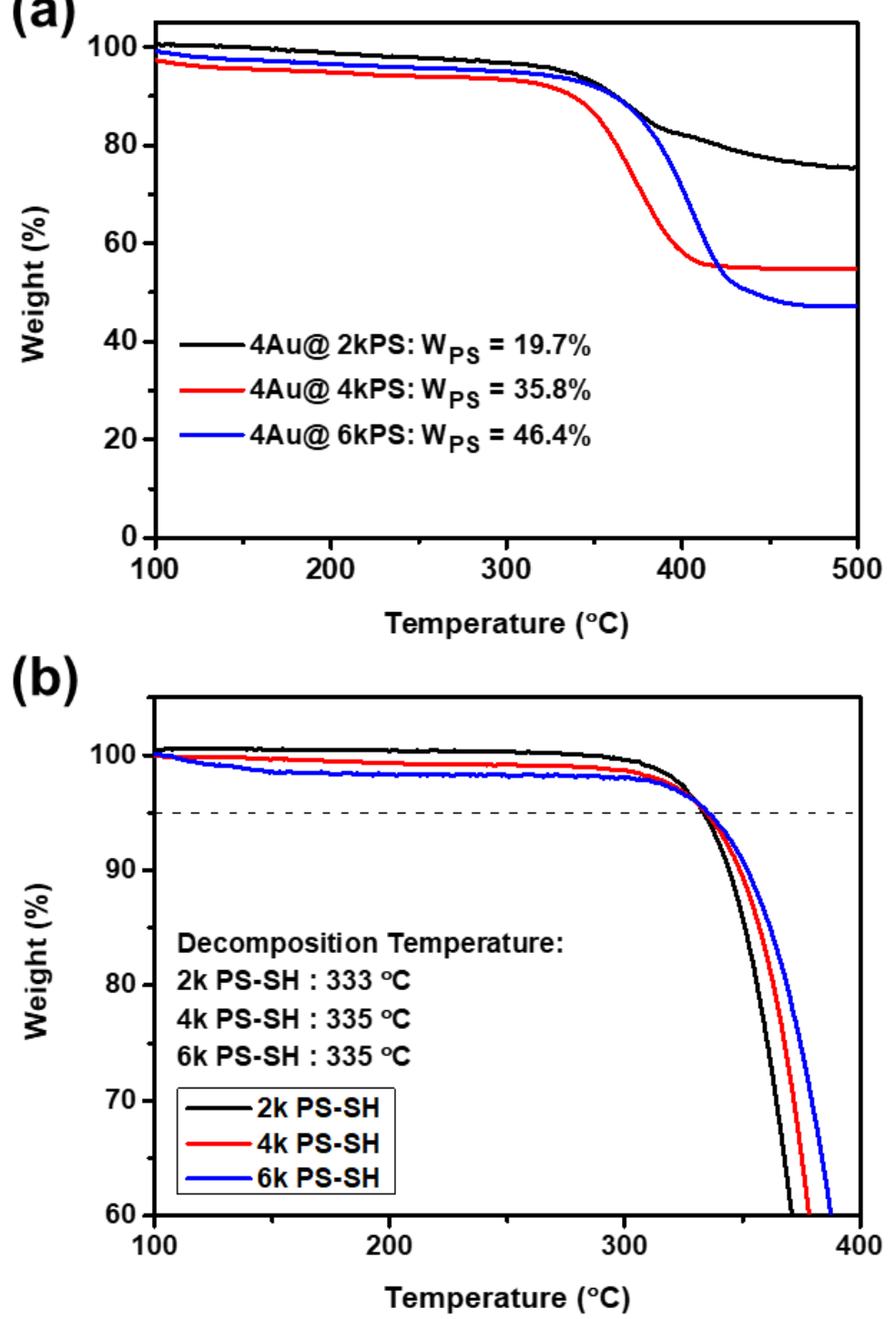

Figure S2. TGA analysis of (a) Au@PS and (b) only PS-SH ligands. The amount of PS-SH ligands in each sample was determined by calculating the weight loss from the thermal decomposition temperature of PS-SH (the temperature corresponding to $5 \%$ weight loss in Figure S2b) to the temperature at which weight $\%$ reaches its minimum. 


\section{- Calculation of Minimum Grafting Density Fully Covering the NP Surface.}

The theoretical minimum value of grafting density for PS-SH ligands to effectively shield the gold surface from interacting with P4VP blocks can be calculated as ${ }^{1}$ :

$$
\Sigma_{\text {min }}=\frac{1}{\pi}\left(\frac{R+R_{\mathrm{g}}}{R_{\mathrm{g}} R}\right)^{2}
$$

where $R$ is the radius of $\mathrm{Au} \mathrm{NP}$ core, and the radius of gyration $R_{\mathrm{g}}=1.15 \mathrm{~nm}$ for $2 \mathrm{k}$ PS-SH, $R_{\mathrm{g}}=1.78$ $\mathrm{nm}$ for $4 \mathrm{k}$ PS-SH, and $R_{\mathrm{g}}=2.18 \mathrm{~nm}$ for $6 \mathrm{k}$ PS-SH.

Table S1. Detailed information of Au@PS used in this study.

\begin{tabular}{c|ccccc}
\hline $\begin{array}{c}\text { PS-grafted } \\
\mathbf{A u ~ N P}\end{array}$ & $\begin{array}{c}\text { Core Diameter } \\
(\mathbf{n m})\end{array}$ & $\begin{array}{c}\text { Ligand } \\
\boldsymbol{M}_{\boldsymbol{n}}\left(\mathbf{k g ~ m o l}^{-\mathbf{1}}\right)\end{array}$ & $\begin{array}{c}\text { Overall Size } \\
\boldsymbol{d}(\mathbf{n m})\end{array}$ & $\begin{array}{c}\boldsymbol{d} / \boldsymbol{L}_{\mathbf{P S}} \\
\left(\boldsymbol{L}_{\mathbf{P S}}=\mathbf{1 0 . 2}\right. \\
\mathbf{1 1 . 8} \mathbf{~ n m})\end{array}$ & $\begin{array}{c}\text { Grafting Density } \\
\boldsymbol{\sigma}\left(\mathbf{c h a i n s} \mathbf{~ n m}^{-2}\right)\end{array}$ \\
\hline $4 \mathrm{Au} @ 2 \mathrm{kPS}$ & $4.3 \pm 0.3$ & 1.8 & $8.0 \pm 0.5$ & 0.78 & 1.14 \\
$4 \mathrm{Au} @ 4 \mathrm{kPS}$ & $4.3 \pm 0.3$ & 4.3 & $11.4 \pm 0.6$ & 1.12 & 1.08 \\
$4 \mathrm{Au} @ 6 \mathrm{kPS}$ & $4.3 \pm 0.3$ & 6.4 & $11.7 \pm 0.8$ & 1.15 & 1.13 \\
\hline
\end{tabular}




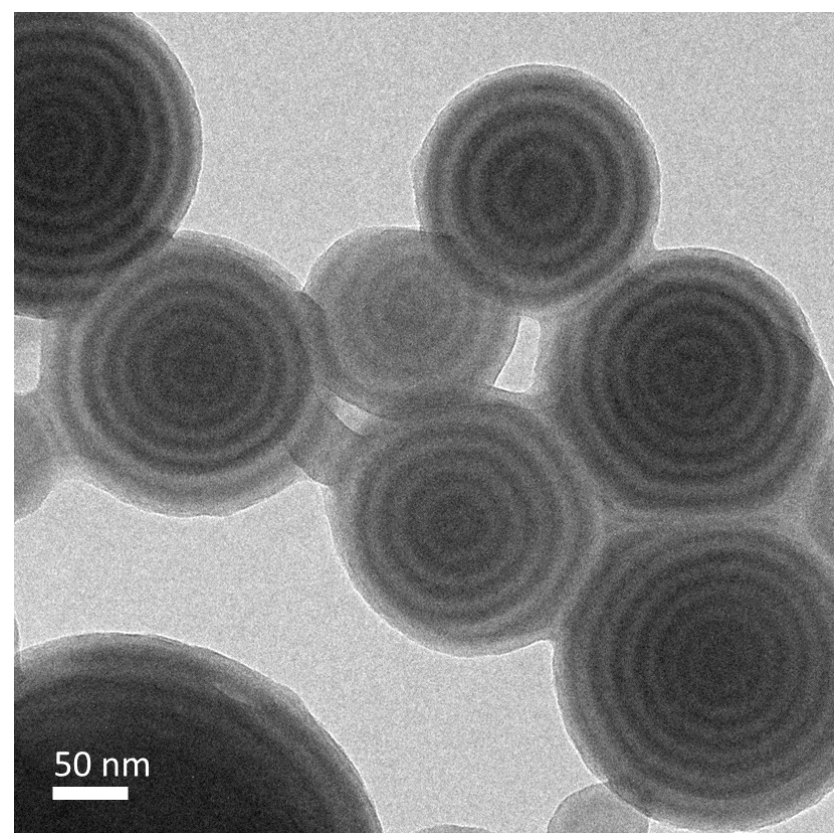

Figure S3. TEM image of pristine PS- $b$-P4VP particles.

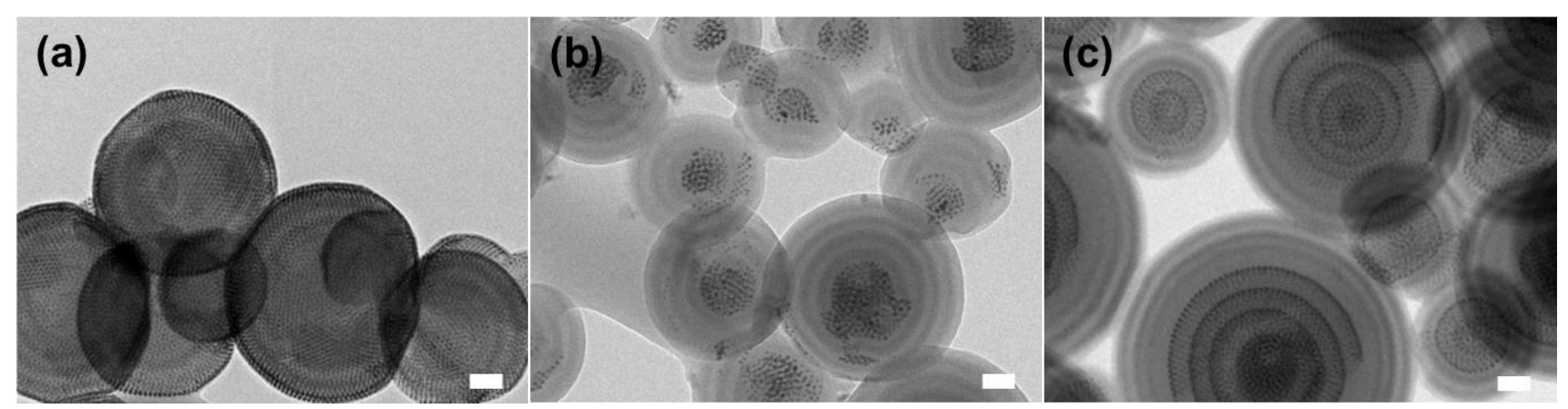

Figure S4. Low-magnification TEM images of PS- $b-\mathrm{P} 4 \mathrm{VP} / \mathrm{Au} @ \mathrm{PS}$ hybrid particles. TEM images of PS- $b$-P4VP particles containing (a) 4Au@2kPS, (b) 4Au@4kPS, and (c) 4Au@6kPS. Scale bars are $50 \mathrm{~nm}$. 

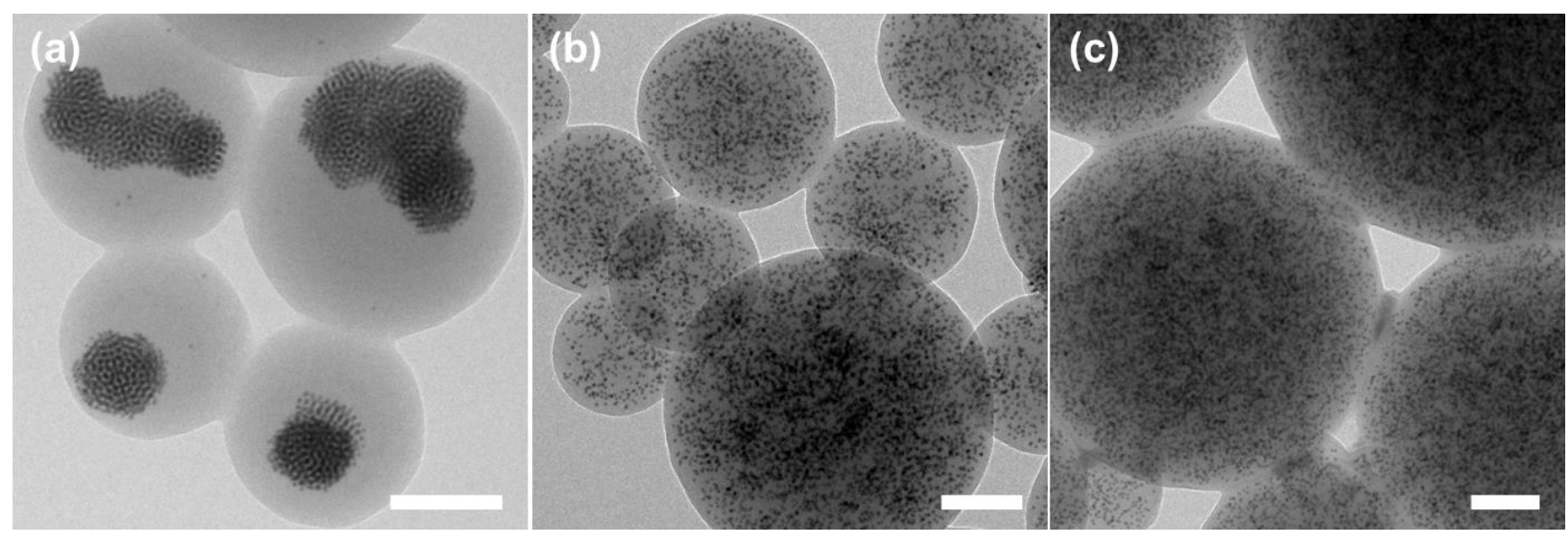

Figure S5. Characterization of Au@PS within a homopolymer PS (hPS) matrix. TEM images of (a) 9khPS/4Au@2kPS, (b) 9khPS/4Au@4kPS, and (c) 9khPS/4Au@6kPS hybrid particles. Scale bars are $100 \mathrm{~nm}$.
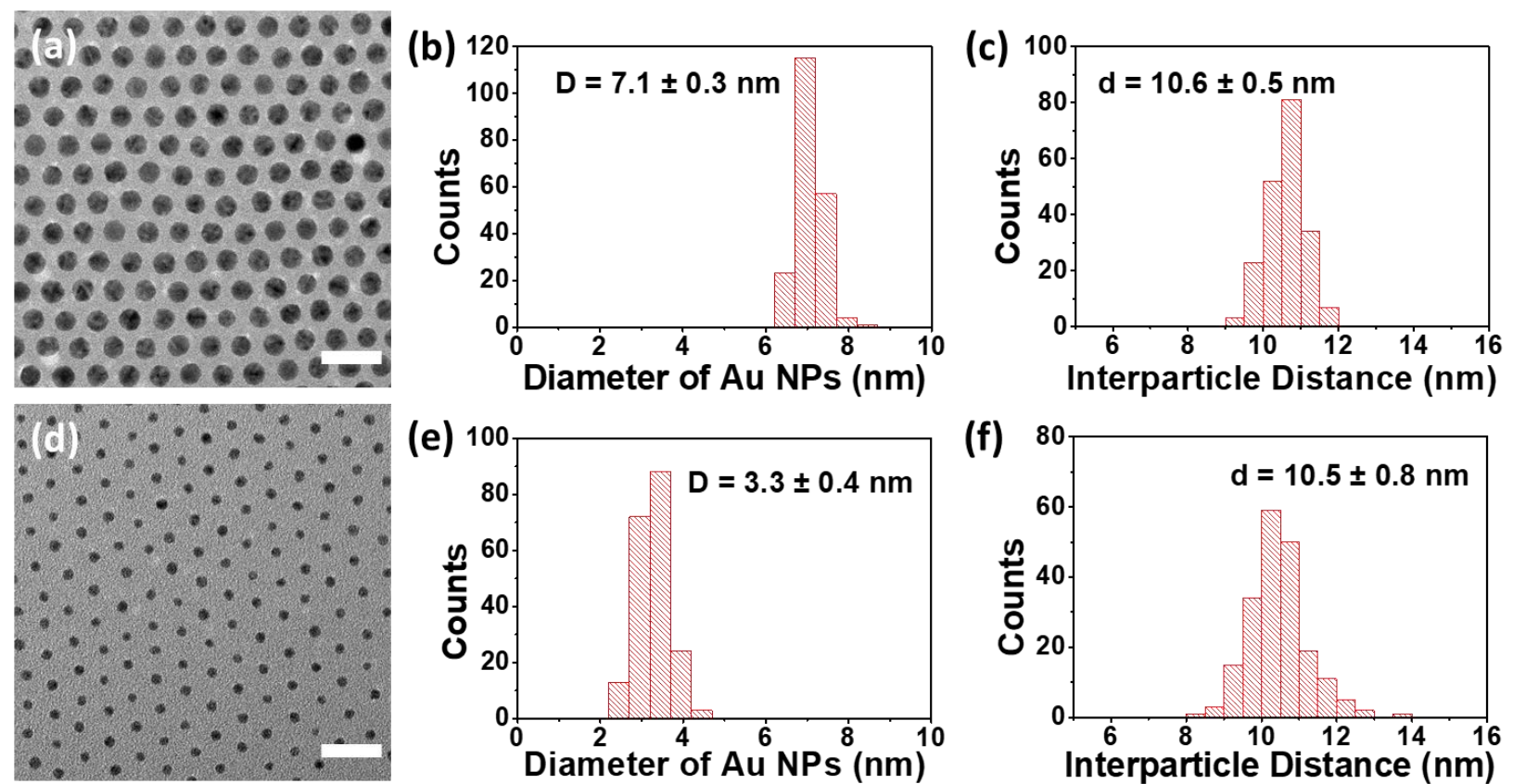

Figure S6. Characterization of $\mathrm{Au} @ \mathrm{PS}$ with different core sizes and $M_{\mathrm{n}}$ of ligands. TEM images and histograms of (a, b, and c) 7Au@2kPS, and (d, e, and f) 3Au@6kPS. Scale bars are 20 nm. 


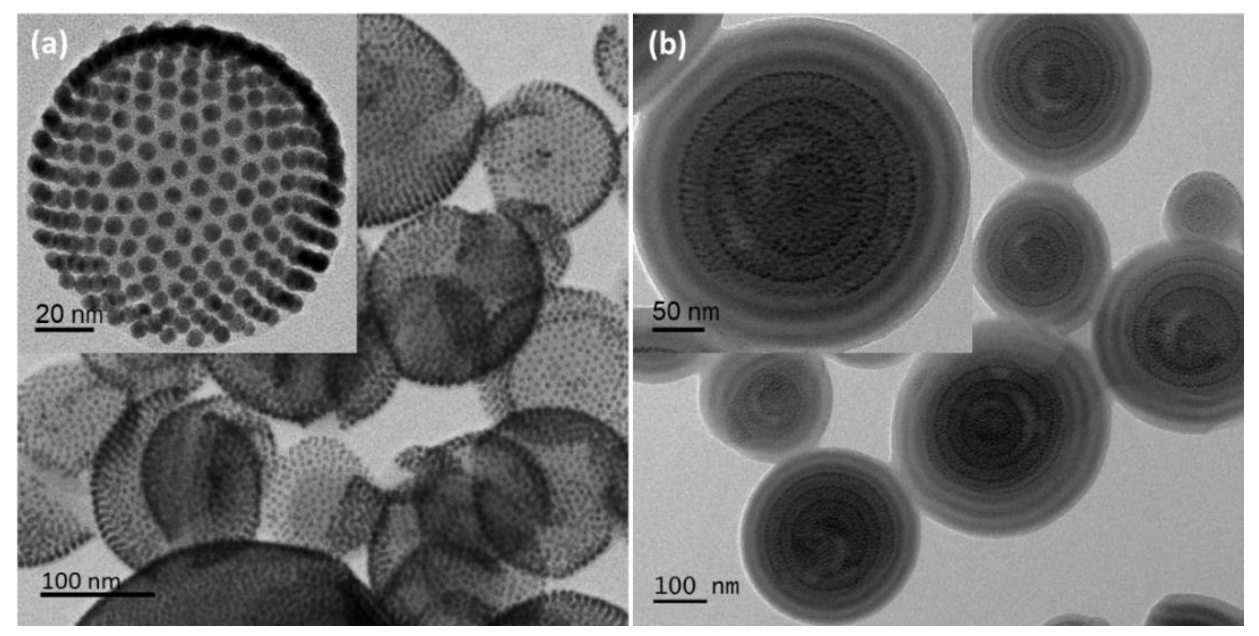

Figure S7. Effect of $P / N$ values on $\mathrm{Au} @ \mathrm{PS}$ assembly within BCP particles. TEM images of PS- $b$ P4VP particles containing (a) 7Au@2kPS $\left(P / N=5.4, d / L_{P S}=1.04\right)$ and (b) $3 \mathrm{Au} @ 6 \mathrm{kPS}(P / N=1.5$, $\left.d / L_{P S}=1.03\right)$. 


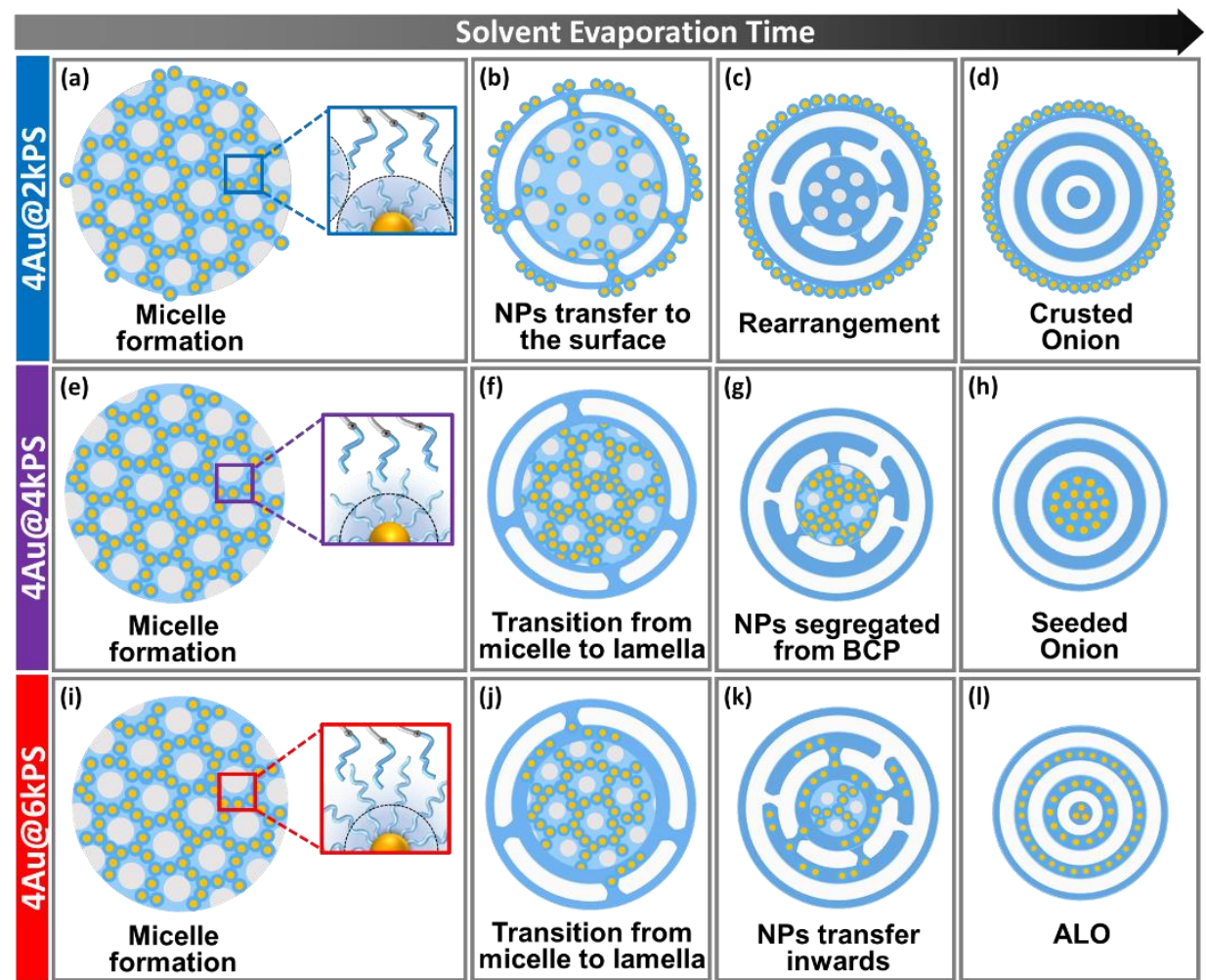

Scheme S1. Schematic illustration of (a-d) PS-b-P4VP/4Au@2kPS, (e-h) PS-b-P4VP/4Au@4kPS, and (i-1) PS- $b$-P4VP/4Au@6kPS particle formation process. 

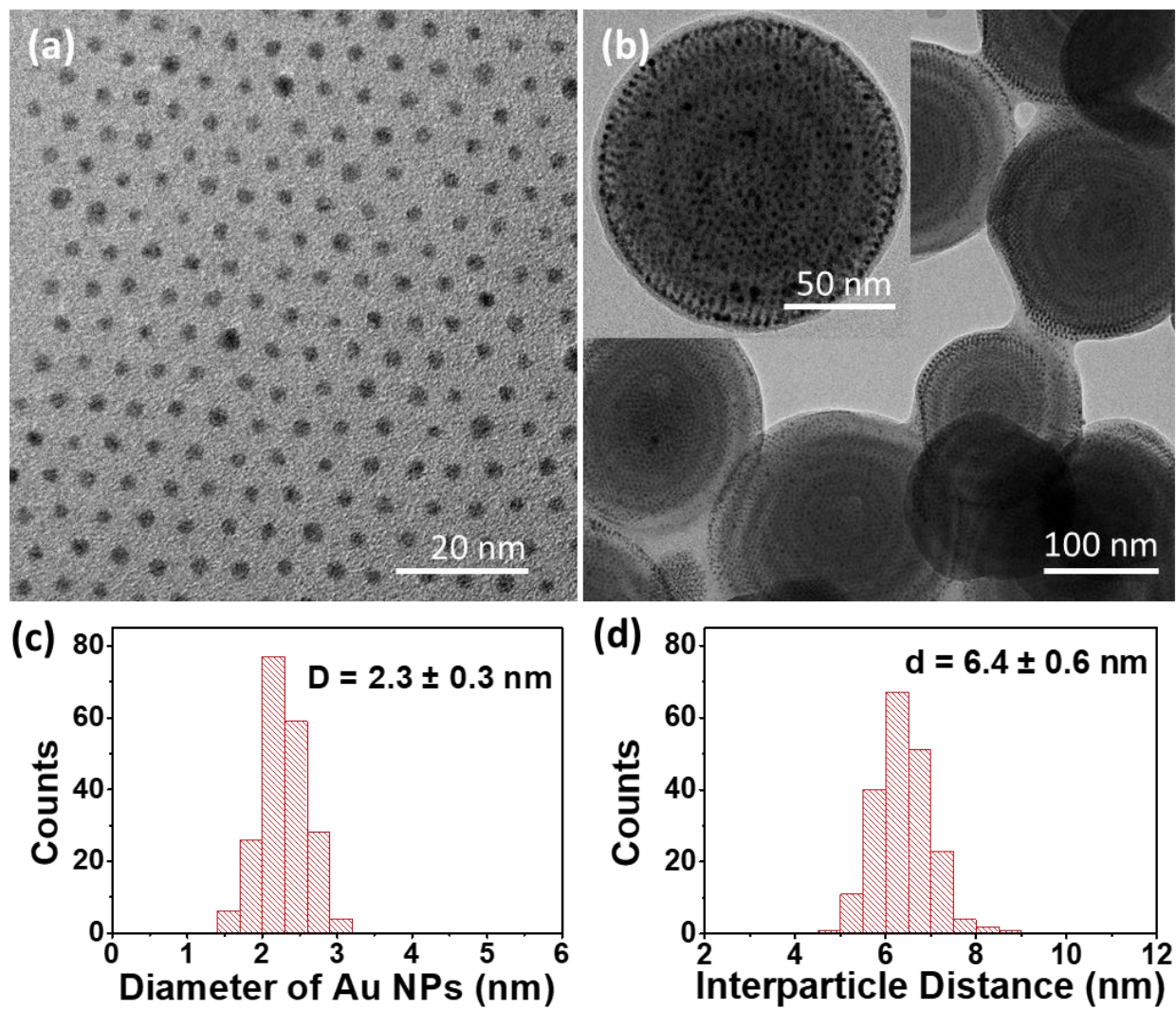

Figure S8. Characterization of $2 \mathrm{Au} @ 2 \mathrm{kPS}$ and the corresponding assembly structure within BCP particles. (a) TEM images and (c, d) histograms of 2Au@2kPS, and (b) TEM image of PS- $b$-P4VP particles containing 2Au@2kPS.

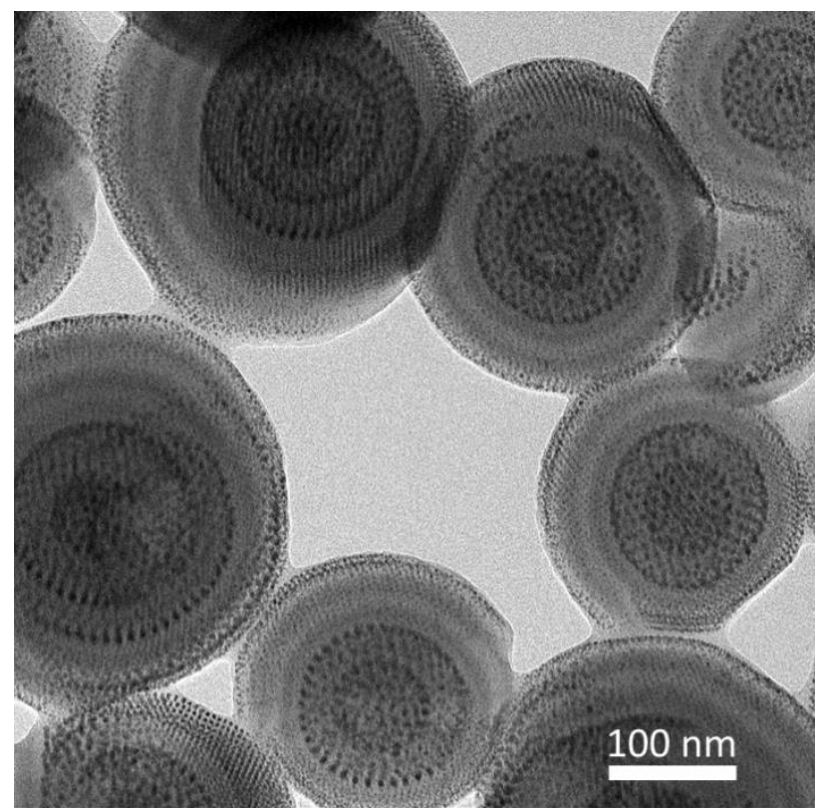

Figure S9. Low-magnification TEM image of PS- $b-\mathrm{P} 4 \mathrm{VP} / \mathrm{Au} @ \mathrm{PS}$ hybrid particles containing 2Au@2kPS and4Au@6kPS. 


\section{References}

(1) Yun, H.; Yu, J. W.; Lee, Y. J.; Kim, J.-S.; Park, C. H.; Nam, C.; Han, J.; Heo, T.-Y.; Choi, S.H.; Lee, D. C.; Lee, W. B.; Stein, G. E.; Kim, B. J. Symmetry Transitions of Polymer-Grafted Nanoparticles: Grafting Density Effect. Chem. Mater. 2019, 31, 5264-5273. 